University of Nebraska - Lincoln

DigitalCommons@University of Nebraska - Lincoln

$1-8-2007$

\title{
Searching for Smart Durable Coatings to Promote Bone Marrow Stromal Cell Growth While Preventing Biofilm Formation
}

\author{
Fereydoon Namavar \\ University of Nebraska Medical Center, 981080 Nebraska Medical Center, Omaha, NE \\ John D. Jackson \\ University of Nebraska Medical Center, 981080 Nebraska Medical Center, Omaha, NE \\ J. Graham Sharp \\ University of Nebraska Medical Center, 981080 Nebraska Medical Center, Omaha, NE \\ Ethan E. Mann \\ University of Nebraska Medical Center \\ Kenneth W. Bayles \\ University of Nebraska Medical Center, kbayles@unmc.edu \\ See next page for additional authors \\ Follow this and additional works at: https://digitalcommons.unl.edu/chemistrycheung \\ Part of the Chemistry Commons
}

Namavar, Fereydoon; Jackson, John D.; Sharp, J. Graham; Mann, Ethan E.; Bayles, Kenneth W.; Cheung, Chin Li; Feschuk, Connie A.; Varma, Shailaja; Haider, Hani; and Garvin, Kevin L., "Searching for Smart Durable Coatings to Promote Bone Marrow Stromal Cell Growth While Preventing Biofilm Formation" (2007). Barry Chin Li Cheung Publications. 13.

https://digitalcommons.unl.edu/chemistrycheung/13

This Article is brought to you for free and open access by the Published Research - Department of Chemistry at DigitalCommons@University of Nebraska - Lincoln. It has been accepted for inclusion in Barry Chin Li Cheung Publications by an authorized administrator of DigitalCommons@University of Nebraska - Lincoln. 


\section{Authors}

Fereydoon Namavar, John D. Jackson, J. Graham Sharp, Ethan E. Mann, Kenneth W. Bayles, Chin Li Cheung, Connie A. Feschuk, Shailaja Varma, Hani Haider, and Kevin L. Garvin 


\title{
Searching for Smart Durable Coatings to Promote Bone Marrow Stromal Cell Growth While Preventing Biofilm Formation
}

Fereydoon Namavar ${ }^{1}$, John D. Jackson ${ }^{2}$, J. Graham Sharp ${ }^{3}$, Ethan E. Mann ${ }^{2}$, Kenneth Bayles ${ }^{2}$, Barry Chin Li Cheung ${ }^{4}$, Connie A.. Feschuk ${ }^{1}$, Shailaja Varma ${ }^{1}$, Hani Haider ${ }^{1}$, and Kevin L. Garvin $^{1}$

${ }^{1}$ Orthopaedic Surgery, University of Nebraska Medical Center, 981080 Nebraska Medical Center, Omaha, NE, 68198

${ }^{2}$ Dept of Pathology \& Microbiology, University of Nebraska Medical Center, 985360 Nebraska Medical Center, Omaha, NE, 68198

${ }^{3}$ Dept. of Genetics, Cell Biology and Anatomy, University of Nebraska Medical Center, 985360 Nebraska Medical Center, Omaha, NE, 68198-5360

${ }^{4}$ Dept of Chemistry, University of Nebraska, Lincoln, 514A Hamilton Hall, Lincoln, NE, 68588

\begin{abstract}
There is a great need to develop methods to regulate cellular growth in order to enhance or prevent cell proliferation, as needed, to either improve health or prevent disease. In this work we evaluated the adhesion, survival and growth of bone marrow stromal cells on the surface of several new ion beam engineered nano-crystals of ceramic hard coatings such as zirconium, titanium, tantalum and cerium oxides. Cell adhesion and growth on the ceramic coatings were compared to adhesion and growth on a nano-crystalline silver coating which is known to possess antibacterial properties. The initial results of a study to determine the effect of nanocrystalline titanium and silver coating on staphylococcus aureus biofilm growth is also discussed.
\end{abstract}

\section{INTRODUCTION}

Joint replacement for arthritic joints is a successful procedure to relieve pain and increase function. For example, in 2005 over 249,000 Americans underwent hip replacement and 488,000 had knee replacements [1]. Shoulders, wrists, and even spinal discs are also being replaced more frequently than ever before. And in the future, we will see a massive increase in all of these joint replacements as the 37 million baby boomers age. Kurtz et al [1] predict that by 2010 hip and knee replacements will number over one million and by 2030 we will see 4.5 million annually. This is an increase of over 400 percent from the present figures.

Most artificial prostheses employ a combination of titanium or cobalt-chrome metallic components combined with various types of plastic. There have been dramatic improvements in the quality and lifespan of such implants with a corresponding decreased incidence of complications. Typically, in regards to orthopedic devices, the primary concerns are wear [2] infection [3,4], and failure of biointegration [5,6]. Wear of the plastic component produces micro particles that cause an immunological response and adjacent bone resorption [2]. Infection, although less common, is devastating to the patient and costly to the health care system [3,4]. Failure of osseointegration of the prosthesis prevents long-term stability which contributes to pain [6], implant loosening [6], and infection [5] that usually necessitates revision. To prevent these complications, prostheses of the future must optimize the material composition of components. 
Optimal component materials will be wear resistant, bactericidal, and encourage biointegration. Specifically, the surface/surface components of the implant should resist wear and especially should resist the generation of particulates as a consequence of wear-induced degeneration. The surface should also be anti-infective through surface morphology or chemistry. For example, silver is known to have broad spectrum antibiotic properties [5]. However to date, the release of the silver cannot be controlled. Finally, the bone contacting surface of the implant should interact positively with mesenchymal stromal cells (MSC) and their pre-osteoblast progeny to promote and maintain osseointegration. This biocompatible surface will lead to tissue integration and vascularization, which will prevent bacterial adhesion and biofilm formation [5]. If possible, the surface should also be designed to be "smart" and boost its anti-infective properties in response to the presence of infectious agents.

We have initiated programs to address the challenge of devising and developing implants with a "triple smart" surface. Ideally, a smart implant will optimize resistance to wear of articulating surfaces of artificial orthopaedic implants, will combine osseointegrative properties in areas where bone is in contact with the implant, and will prevent bacterial biofilm formation. We believe the development of a smart coating to prevent biofilm formation while promoting adhesion and growth of stem cells is of great importance to the longevity of orthopaedic arthroplasty implants and internal and external orthopaedic fixation devices. In this paper, we report preliminary results of the adhesion, survival and growth of bone marrow stromal cells on several ultrahydrophilic nano-crystal film surface coatings. We also report on staphylococcus aureus growth on titanium and silver nano-crystal surface coatings.

\section{EXPERIMENTAL PROCEDURES}

\section{$\underline{\text { Nanocrystalline films }}$}

Fabricating biocompatible surfaces with a well defined nanostructure and morphology by conventional techniques is very difficult. However, ion beam assisted deposition (IBAD) can provide the possibilities of designing and engineering nanocrystalline coatings with well defined structures, chemistry and morphology. The IBAD combines physical vapor deposition with concurrent ion beam bombardment (e.g. N, O, and Ar) in a high vacuum environment (figure 1a). All nanocrystalline samples reported here were deposited in a 41 "x45"x37" (2" thick) stainless steel water cooled ultralow vacuum chamber $\left(10^{-8}\right.$ torr), (figure $\left.1 \mathrm{~b}\right)$. The IBAD system is comprised of a RF Ion Gun that supplies ions at energies up to $1500 \mathrm{eV}$, a DC ion Gun with an ion density of $3 \mathrm{~A}$ at energies up to $150 \mathrm{eV}$, a thermal evaporation source, and a $10 \mathrm{~kW}$ electron gun with a programmable sweep multi pocket four electron beam evaporation source. Energetic ions (ionic hammers) are employed to produce "engineered nano-crystals" with superior properties (hardness and wettability) that are then "stitched" to any substrate by ion bombardment. Furthermore, IBAD is applied to produce materials with exceptional chemical, physical, mechanical and nano-structural properties that nature does not allow to occur in equilibrium conditions. 

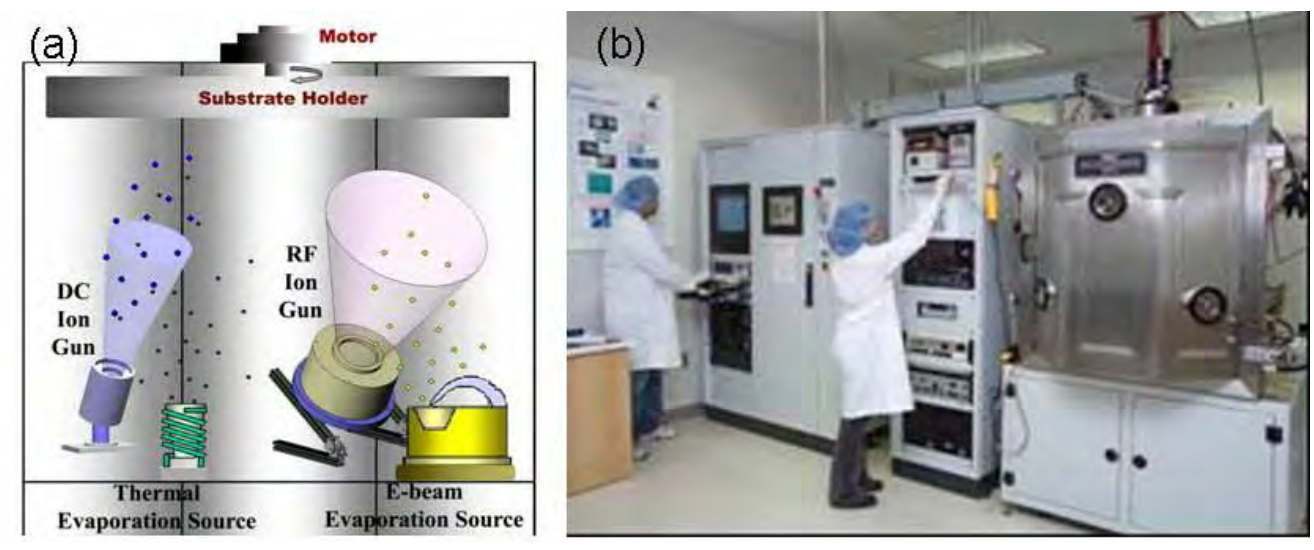

Figure 1 a) Ion Beam Assisted Deposition System b) Schematic of twin IBAD process. The process combines physical vapor deposition (evaporation) with concurrent ion bombardment to produce a wide range of smart coatings with exceptional adhesion to virtually any substrate.

\section{Cloned bone marrow stromal cell line}

The stromal cells, OMA-AD, are utilized to determine the effect of nanostructure coatings and their material composition on cell growth. These cells were derived from the bone marrow of a female $\mathrm{C} 57 \mathrm{Bl} / 6$ mouse by repeated trypsinization of the adherent layer of a longterm bone marrow culture. The cell line was cloned by limiting dilution plating and was expanded in Fischer's medium containing 10\% fetal bovine serum (FBS), $10 \%$ horse serum (HS), $2 \mathrm{mM} \mathrm{L-glutamine}$ and $1 \times 10^{-6} \mathrm{M}$ hydrocortisone. The morphology of the cells shows a wide spread cytoplasm similar to a blanket cell [7]. OMA-AD supports the maintenance of primitive mouse hematopoietic stem cells [8] and human hematopoietic cells [9].

OMA-AD cells were cultured at $37^{\circ} \mathrm{C}$ in a humidified incubator containing $5 \% \mathrm{CO}_{2}$ in air for up to 12 days. The growth medium was RPMI 1640 medium, $10 \%$ fetal bovine serum (FBS), $10 \%$ horse serum (HS), 100 units $/ \mathrm{ml}$ penicillin, $100 \mu \mathrm{g} / \mathrm{ml}$ streptomycin, $2 \mathrm{mM}$ L-glutamine and $1 \times 10^{-6}$ hydrocortisone. Alamar Blue assay [10] and direct cell counting methods were used to determine the growth of OMA-AD on the different nanoengineered surfaces.

\section{Biofilm assays}

Staphylococcus aureus biofilm was grown on either elemental nanocrystalline titanium or silver which was deposited into silicon substrates in a BST FC 270 Flow Cell apparatus from BioSurface Technologies, Corp. (Bozeman, MT) as follows. Six-hour trypticase soy broth (TSB) cultures of $S$. aureus strain 15981 were diluted in $3 \mathrm{ml}$ of $\mathrm{TSB}$ to an $\mathrm{OD}_{600}=0.05$ and were used to inoculate the flow cell chambers, whose setup was performed according to the manufacturer's recommendations. Before inoculation, culture media $(0.1 \times \mathrm{TSB}+0.25 \%$ glucose $)$ was pumped through the flow cells at a rate of $0.75 \mathrm{ml} \cdot \mathrm{min}^{-1}$ for 1 hour. After inoculation, the flow cell reactor was incubated statically for 120 minutes at $37^{\circ} \mathrm{C}$, and then the media flow was resumed. After incubation, for 24 hours at $37^{\circ} \mathrm{C}$, the media flow was stopped and the bacterial growth on each chip was washed three times with $1.0 \mathrm{ml}$ of PBS buffer. The bacterial growth was then scraped from the surface and the viable cells remaining were quantified using standard dilution plating techniques. 


\section{EXPERIMENTAL RESULTS}

In vivo, much of the proliferative activity in bone cell development is associated with mesenchymal precursors. However, in vitro, osteoblast cell lines often have characteristics resembling tumor cancer cells, including dysregulated cell proliferation. Consequently, their growth on surface coatings may not be typical of normal cells. Because of these concerns over the use of osteoblast cell lines, the current studies were performed using a cloned bone marrow stromal cell line from C57B1 mice termed OMA-AD cells. This is a spontaneously immortalized undifferentiated stromal cell population that resembles multipotential mesenchymal stromal cells (MMSC). OMA-AD cell line duplicates, in vitro, all of the characteristics of primary mesenchymal stem cells and is a valid experimental model to probe the impact of nanocrystalline hard ceramic coatings on the attachment, survival and growth of bone marrow stromal cells.

The engineered nanocrystalline metal, such as titanium and silver, and transparent ceramic films deposited on silicon, quartz, and glass substrates were placed in wells of culture plate containing specifically formulated growth medium. Depending on the experiments, defined numbers of OMA-AD cells were added to each well and the plates were cultured. Figure 2a shows Alamar blue assay results for growth of OMA-AD on a nanostructure of $\mathrm{ZrO}_{2}$ (with a zero contact angle and a total wettability to water), $\mathrm{Ta}_{2} \mathrm{O}_{5}, \mathrm{TiN}$, and on two different silver (Ag) coatings deposited under different IBAD deposition conditions. As shown here, cubic zirconia supported the highest cell growth and silver supported the lowest OMA-AD growth. Figure $2 b$ shows growth of cloned bone marrow stromal cells, OMA-AD, on transparent tantalum oxide deposited on quartz substrate.

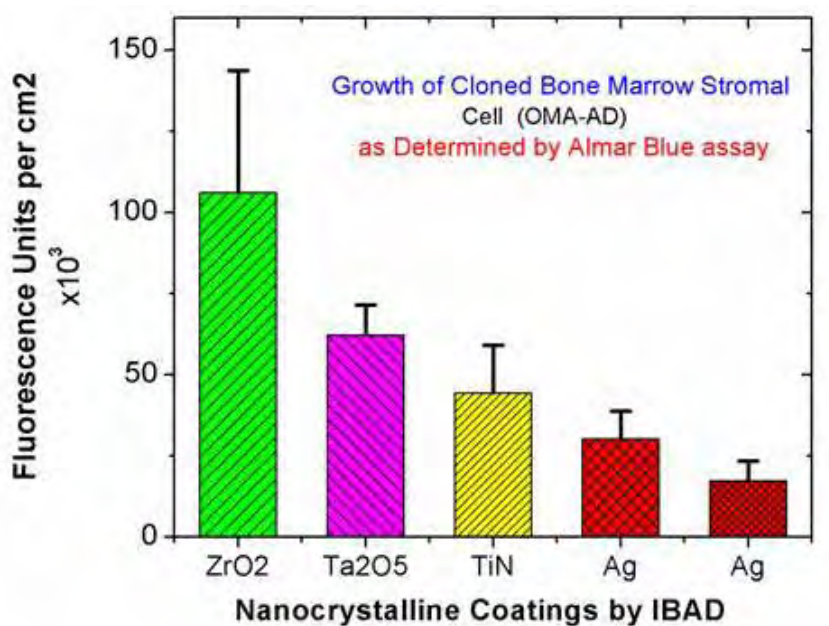

(a)

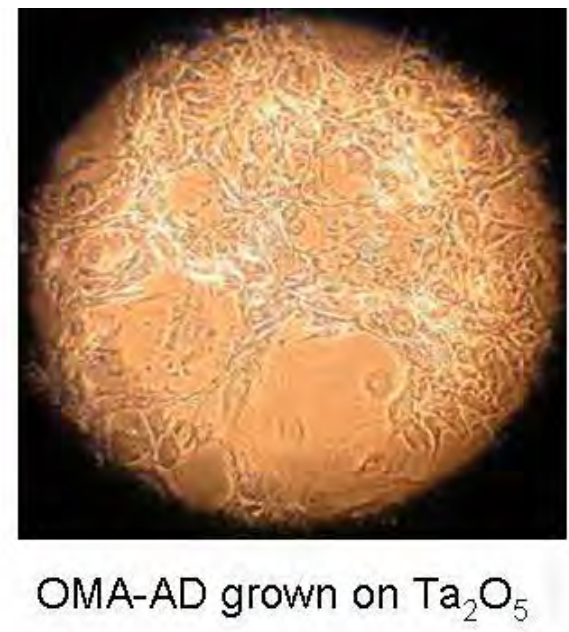

(b)

Figure 2a Growth of OMA-AD (as determined by Alamar Blue Assay) on nanocrystalline coatings of cubic zirconium, tantalum oxide, titanium nitrite, and two nanocrystalline silver coatings produced by two different IBAD processes. 2b Typical morphological appearance of OMA-AD grown on transparent $\mathrm{Ta}_{2} \mathrm{O}_{5}$ deposited on quartz substrate.

Figure 3a shows the growth of OMA-AD on nanocrystalline titanium and silver. Silver demonstrated the least support of OMA-AD when compared to titanium and ceramics (see also figure 2a). Silver consistently suppresses the growth of bone marrow stromal cells. Figure $3 b$ shows an atomic force microscopy (AFM) image of nanocrystalline titanium with a roughness of 
$16 \mathrm{~nm}$, and figure 3c shows an AFM image of nanocrystals of silver with a roughness of $116 \mathrm{~nm}$. Both of these nanocrystalline coatings were deposited by IBAD using Argon bombardment.

To assess the impact of the nanocrystalline coatings on the growth of bacterial biofilm, we performed continuous flow biofilm assays using a common nosocomial pathogen, Staphylococcus aureus. Samples were placed in a flow cell chamber and inoculated with $S$. aureus strain 15981 and grown for 24 hours. The total number of viable cells (see figure 4a) remaining after washing the samples was reduced on the nanocrystalline silver deposited silicon $\left(3.58 \pm 0.78 \times 10^{8}\right)$ compared to those that were deposited with nanocrystalline titanium $(1.19 \pm$ $\left.0.29 \times 10^{9}\right)$. These initial results suggest that nanocrystalline silver deposited with argon bombardment reduces bacterial viability, which is consistent with OMA-AD results.

Figure $4 \mathrm{~b}$ and $4 \mathrm{c}$ show the contact angle of IBAD fabricated nanocrystals of titanium and sliver deposited on semiconductor grades of silicon substrates. The titanium nanocrystal sample has a roughness of about $16 \mathrm{~nm}$ (figure $3 \mathrm{~b}$ ), with a fine nanocrystal grain, and a contact angle of about 4 degrees. Even though the top few atomic layers of titanium nanocrystals are oxidized in air (even for the samples that are deposited in an ultra high vacuum system), our results suggested that they are less supportive of OMA-AD growth than the IBAD produced nanocrystals of $\mathrm{TiO}_{2}$ with anatase crystal structure. The silver nanocrystal sample has a roughness of about $116 \mathrm{~nm}$ (figure 3c) and a contact angle close to 90 degrees; while the contact angles of orthopaedic grade materials measured in the range of around 60 degrees. Lower contact angle translates to wettability to water and can be explained by the Wenzel model [11] of increase of actual surface to apparent surface area. Increased wettability (hydrophilicity) may encourage cell adhesion and growth as seen with the OMA-AD, and encourage biofilm growth as see on the nanocrystalline $\mathrm{Ti}$ (figure 4a). While large contact angles that have decreased wettability (hydrophobia), as seen with nanocrystalline Ag, have been found to support only minimal cell growth (figure $2 \mathrm{a} \& 4 \mathrm{a}$ ). In principal, one can apply (as we have done here) the Wenzel model and design surface coatings to amplify hydrophilic or hydrophobic properties.

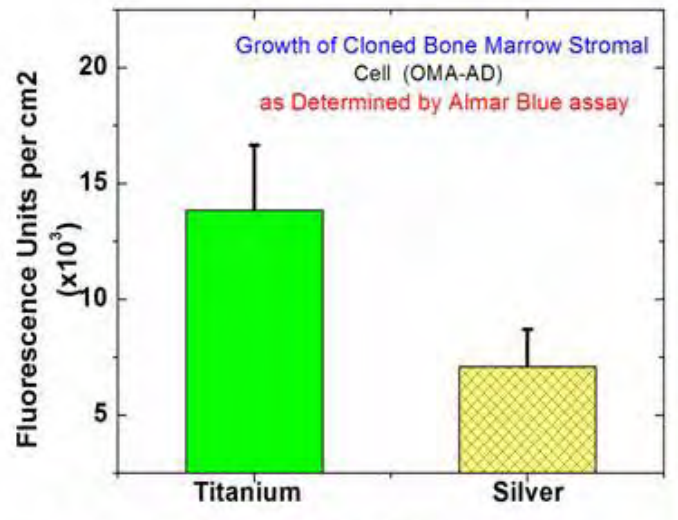

(a) Nanocrystalline Coatings by IBAD

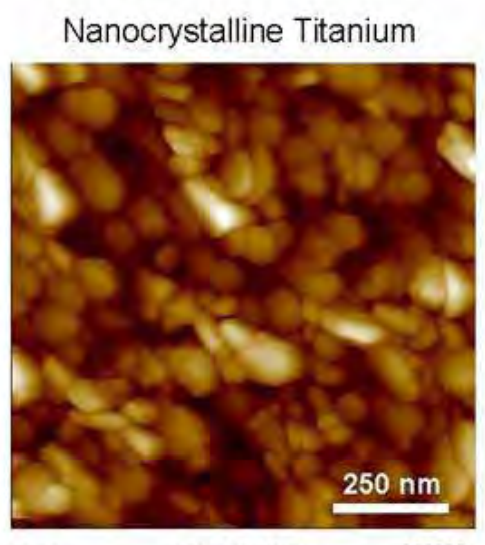

(b)
RMS 16.5

Figure 3 a) Comparison of OMA-AD growth on nanocrystalline Ti to growth on nanocrystalline Ag. (b) and (c) surface morphology and roughness for nanocrystalline Ti and Ag respectively. 

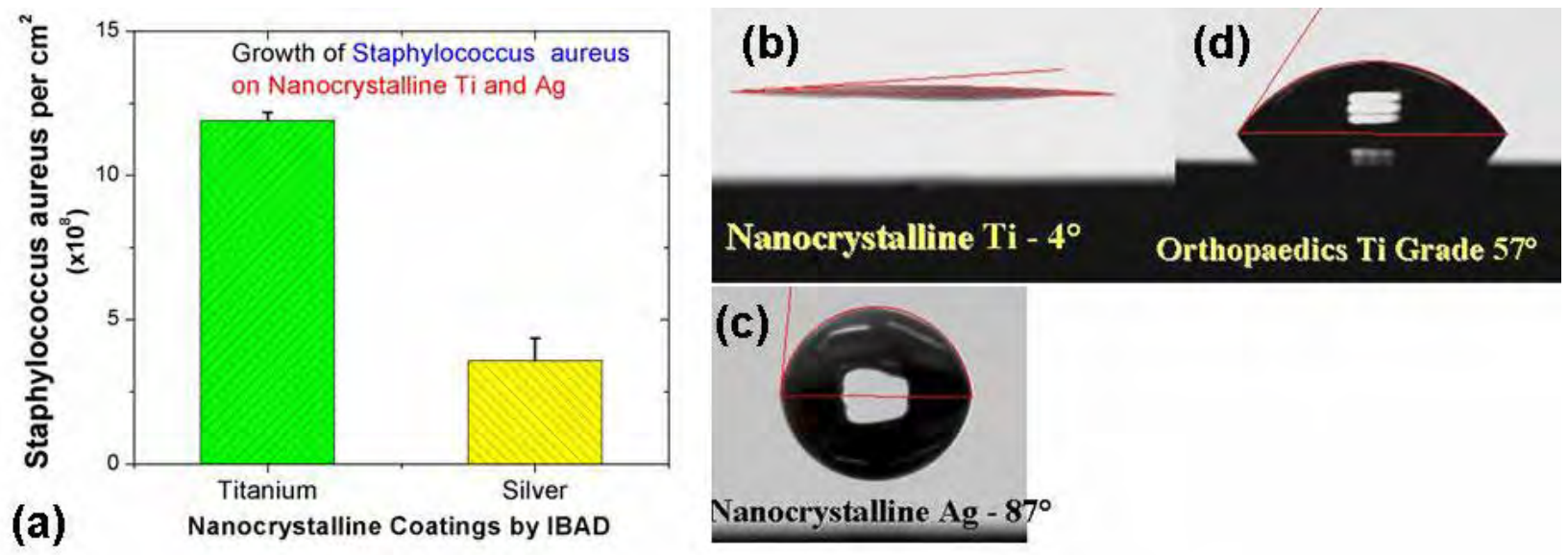

Figure 4 a) Comparison of staphylococcus aureus growth on nanocrystalline Ti to growth on nanocrystalline $\mathrm{Ag}$, (b) Contact angle for nanocrystal coating of Ti, indicating it has total wettability to water and thus possesses hydrophilic properties (c) Nanocrystal coating of silver with hydrophobic properties (d) Orthopaedic Ti component.

\section{DISCUSSION AND CONCLUSIONS}

Nanostructured substrates exhibited differences in their ability to support the growth of OMA-AD cells. Nanostructurally stabilized cubic zirconia and tantalum oxide exhibited the highest support of the OMA-AD cells, while Ag showed the least support. Our data indicates that nanostructures and chemical properties of surfaces both influence the attachment and growth of OMA-AD. Furthermore, our preliminary results showed reduced staphylococcus aureus attachment and growth on sliver nanostructures. However at this time, the impact of the hydrophobic characteristic of nanocrystalline silver on attachment and growth of OMA-AD cells and bacteria is not clear and therefore warrants further studies.

Hydroxyapatite (HA) has been studied for decades because of their bioactive properties "as they bond to bone and enhance bone tissue formation" [12]. However, concerns have been raised about the bioabsorption of the HA layer, the mechanical strength of the HA layer [12, 13] and the HA layer debonding from the metal implant $[13,14]$. It is possible that our nanostructured substrates may address the concerns with HA. First, it appears that the high wettability of our zirconium and tantalum oxides may play an important role in osteointegration of artificial implants. Then these ceramics are attractive not only because of the possibility of their osteoconductivity properties, but also because of their mechanical strength and the possibility of their excellent adhesion to metallic components because of the IBAD process.

\section{ACKNOWLEDGMENTS}

FN, HH, CLC gratefully acknowledges partial support from a Nebraska Research Initiative grant.

\section{REFERENCES}

1. S. Kurtz, E. Lau, M.A. Ke Zhao, F. Mowat, K. Ong and M Halpern, The future burden of hip and knee revisions: U.S. projections from 2005 to 2030. Presented at the American Academy of Orthopaedic Surgeons, Chicago, IL, 2006 (unpublished). 
2. M. Jasty, "Prosthetic loosening in total hip replacements," in Revision Total Hip Arthroplasty, editors J. V. Bono et.al, (Springer-Verlag, New York, Inc., 1999).

3. A.D. Hansen and J.A. Rand, American Academy of Orthopaedic Surgeons Instructional Course Lectures, Edited by J. D. Zuckerman, Vol. 48, 111-122, 1999.

4. K.L. Garvin and J.A.Urban, Orthopaedics. Editors R. Fitzgerald, H. Kaufer, and A. Malkani, (Mosby, Philadelphia, 2002), Chap.7, pp 755-768.

5. L.G. Harris and R.G. Richards, Injury, Int. J. Care Injured, 37, S3-S14, (2006).

6. M. Viceconti, A. Pancanti, M. Dotti, F. Traina and L. Cristofolini, Med Biol Eng Comput. 42, pp. 222-229, (2004).

7. T.M. Dexter, L.H. Coutinho, E. Spooncer, C.M. Heyworth, C.P. Daniel, R. Schiro, J.Chang and T. D.Allen, Ciba Found Symp, 148, pp. 76-95 (1990).

8. K. Klarmann, M. Ortiz, M. Davies and J.R. Keller, Blood, 102(9), pp. 3120-3128 (2003).

9. S.J. Pirruccello, J.D. Jackson and J.G. Sharp, Leuk Lymphoma, 13(1-2), pp.169-178 (1994).

10. S. A. Ahmed, J. R. M. Gogal and J.E. Walsh, Journal of Immunological Methods, 170(2), pp. 211-224 (1994).

11. Wenzel, R. N.,. Ind. Eng. Chem. 28, 988 (1936).

12. A. El-Ghannam, Expert Review Medical Devices 2(1), 87-101 (2005).

13. B.D. Ratner, Journal of Dental Education 65 (12), 1340-1347 (2001).

14. O. Reikeras and R. B.Gunderson, Acta Orthop Scand. 73(1), 104-8 (2002). 